\title{
ENFERMAGEM E INSTÂNCIAS COLEGIADAS DE DECISÃO: UM ESTUDO DA REPRESENTAÇÃO DA ENFERMAGEM NOS CONSELHOS MUNICIPAIS DE SAÚDE*
}

Selma Regina de Andrade Marino**

Ångela Maria Blatt Ortiga***

\begin{abstract}
RESUMO: Este trabalho procura levantar aspectos atuais sobre a operacionalização de uma efetiva integração do enfermeiro e da enfermagem na formulação de políticas de saúde, analisando sua representação junto aos Conselhos Municipais de Saúde em Santa Catarina, até 1992. Adotou-se, como base teórica, as concepções organizacionais de mecanismos de coordenação entre administração pública e sociedade civil. Esta análise inclui o relato do processo histórico de integração de profissionais de saúde nas instâncias colegiadas do setor. Utilizou-se a técnica de análise documental cujos dados, extraídos de fonte secundária, apontam uma baixa frequência de representação da categoria nestes Conselhos, principalmente na condição de representante de profissionais de saúde. A importåncia e necessidade de um aumento nestas atividades são discutidas.
\end{abstract}

ABSTRACT: The present paper explores some current aspects of the nurse's and nursing involvement in the formulation of health policy. Ways for the operationalization of such a role are discussed under the focus of an analysis of the nurse's participation in the Conselhos Minicipais de Saúde (CMS) of Santa Catarina up to 1992, including a historical description of the health workers integration to the sectorial policy. The theoretical framework of the present analysis was the organizational concepts for coordination between citizen participation and public administration. The documental survey, extracted from secondary sources, points to a low incidency of nursing participation in the CMSs as health professionals representatives. The importance and opportuness for increasingt such a participation are discussed.

UNITERMOS: Conselhos de Saúde - Políticas de Saúde - Representação Social.

\section{INTRODUÇÃO}

Apesar de existirem formas bastante variadas de integração entre segmentos sociais e o poder público $(9,10)$, no setor saúde, o mecanismo estabelecido fundamentalmente pela Lei Orgânica da Saúde (Lei 8.080/90) e Lei 8.142/90, prevê a participação de diversos setores sociais, inclusive dos profissionais de saúde, através de seus representantes, nas instâncias colegiadas (Conselhos e Conferências de Saúde), em im- plantação nas diferentes esferas de Governo.

Os Conselhos de Saúde, instâncias privilegiadas de decisão, vêm se consolidando como órgãos integrantes da estrutura de gestão da saúde, acenando para a possibilidade de melhorar o acerto das decisōes e dar, assim, maior consenso e força às ações. Tais Conselhos, conforme principios legais, devem ser compostos prioritariamente por representantes dos usuários do sistema e representantes do conjunto dos segmentos governamentais, prestadores

\footnotetext{
- Trabalho apresentado como Tema Livre no $45^{\circ}$ Congresso Brasileiro de Enfermagem, Olinda-Recife, 28 de novembro a 3 de dezembro de 1993.

** Gerente de Descentralizaçăo das Unidades Ambulatoriais/Secretaria de Estado da Saúde/SC.

*** Chefe de Acompanhamento da Municipalizaçăo/Secretaria de Estado da Saúde/SC.
} 
de senviços e profissionais de saúde.

Se a estratégia de atuação do profissional nesse campo de negociaçăo enfatiza, por um lado, a dimensão técnica do processo participativo, por outro, parece favorecer um aperfeiçoamento da atuaçåo política das categorias, de modo a intervir, efetivamente, na formulação e controle dos programas e projetos do setor saú$\mathrm{de}^{(6)}$. Com uma representatividade de mais de $50 \%$ dos profissionais de saúde, é necessário que a enfermagem se organize intemamente para participar de forma ativa e crítica da construção da nova estrutura de gestão e de organização do Sistema Único de Saúde(1).

Tendo por base as concepções organizacionais de mecanismos de coordenação entre poder público e sociedade civil, pretende-se, neste trabalho, identificar a representação dos profissionais de saúde nos Conselhos Municipais de Saúde de Santa Catarina, comparativamente aos demais segmentos, bem como caracterizar a representação do enfermeiro e da enfermagem no segmento de profissionais de saúde nestes conselhos.

Desse modo, ao discutir aspectos da integração do profissional de saúde, em particular da enfermagem, como parte do segmento social também interessado na formulaçăo de políticas de saúde, espera-se contribuir para a reflexăo e possiveis definições sobre os rumos que tais profissionais pretendem estabelecer e seguir neste setor.

\section{A INTEGRAÇÃO DOS SEGMENTOS PRO DOȘ́ETOR SAÚDE}

O modo de integraçåo dos segmentos sociais na administração pública, particularmente no setor saúde, faz parte de um processo de transformação, amplo e ainda em movimento, do modelo assistencial de saúde no País. Como item para reformulação do sistema de gestão na esfera setorial, a participação dos diferentes segmentos interessados, no início dos anos 80 , caracterizou um traço marcante nas propostas e medidas político-institucionais.

A preocupação com a inclusão de outros segmentos representativos nos assuntos do setor foi delineada a partir do Simpósio Nacional de Saúde, realizado em 1979, cujas conclusões ressaltaram que as modificações necessárias na Política Nacional de Saúde somente seriam possiveis na medida em que diferentes setores da sociedade se façam representar, através de suas organizaçठes proprias e, especialmente, nos níveis decisórios do sistema de saúde ${ }^{(5: 79)}$. Tais conclusões deram origem ao Programa Nacional de Serviços Básicos de Saúde (PREVSAÚDE) e, posteriormente, ao Plano de Reorientaçăo da Assistência à Saúde no Âmbito da Previdéncia Social. Estes documentos propunham a reversão do modelo médico-assistencial vigente, cuja estratégia de implementação apresentava um delineamento de natureza política, fundamentada nos principios de gradualidade no processo de reorientaçăo do modelo, e na participaçáo ativa de vários segmentos da sociedade na conduçăo dessa mudança.(8:298)

O principal instrumento para a integração programática das instituições e dos senviços de saúde federais, estaduais e municipais foi representado pelos convênios das Ações Integradas de Saúde (AIS), nos quais foram definidas as Comissões de Saúde, nos diferentes níveis, como estruturas de gerência e acompanhamento destas ações. Nessas instâncias colegiadas, no entanto, não houve uma integração de representantes dos profissionais de saúde, mas apenas uma representação institucional, através de técnicos de diferentes formações, de cada um dos prestadores de serviços de saúde atuantes na área de abrangência. Nos diferentes níveis, essas Comissões eram assessoradas, na maioria dos casos, por Secretarias Técnicas, compostas por profissionais multidisciplinares, sem que houvesse, contudo, a definção do perfil e padrão de desempenho para participação desses profissionais.

Em 1986, com a convocação da VIII Conferência Nacional de Saúde (CNS), os debates tomaram evidente a necessidade de uma ampla reforma setorial, que ultrapassasse os limites de uma reforma administrativa e financeira. O movimento para a Reforma sanitária propôs ampliar o próprio conceito de saúde e sua correspondente ação institucional, assegurando, no seu sentido mais abrangente, a saúde como um direito do cidadăo e um dever do Estado.

Em relação à reformulação do Sistema Nacional de Saúde, as conclusões dessa Conferência resultaram na proposta de criação de um 
Sistema Único de Saúde, que representasse a construção de um novo arcabouço institucional, coordenado por um único gestor em cada esfera de governo. No âmbito institucional, esta proposta foi inicialmente viabilizada por meio da implementação, através de convênio, do Sistema Unificado e Descentralizado de Saúde (SUDS). Nesses convênios estava prevista a criação de inståncias colegiadas gestoras das ações de saúde, de modo a assegurar a participação dos segmentos sociais, através de seus representantes nestes colegiados. A concepção estrutural do colegiado consistiu de instalação de Comissões (Comissão Interinstitucional de Saúde, em nivel estadual e Comissões Interinstitucionais Municipal ou Locais de Saúde, em nivel municipal) e dos Conselhos Estaduais e Municipais de Saúde, com previsão, de modo amplo, da participação de entidades governamentais e sociedade civil, mantendo vago ou mesmo ausente a representação de profissionais de saúde.(4)

Durante este periodo, os princípios básicos aprovados pela VIII Conferência Nacional de Saúde foram transformados, em sua maioria, em dispositivos da constituição de 1988 , posteriormente regulamentados pela Lei Orgânica da Saúde (Lei 8.080, de 19/09/90). Em relação aos aspectos gerenciais, os dispositivos foram regulamentados pela Lei 8.142 , de $28 / 12 / 90$, que dispõe sobre a participação dos segmentos sociais no Sistema Único de Saúde (SUS), definindo, como instâncias colegiadas, os Conselhos de Saúde e as Conferências de Saúde, para os três níveis de governo.

Com a assinatura dos Convênios SUS/91, e a regulamentaça dos aspectos operacionais para a implantação do SUS (Norma Operacional Básica MS-INAMPS 01/91) foi definida a participação dos segmentos representativos do setor de forma paritária: $\mathbf{5 0 \%}$ da composição por representantes dos usuários do sistema e $50 \%$ de representantes do governo, de prestadores de serviços e de profissionais de saúde. De acordo com essas diretrizes, estão sendo criados e implementados os Conselhos Estaduais e Municipais de Saúde, através de leis específicas, com a finalidade de formular as diretrizes das políticas de saüde e fiscalizar a execução das ações. Esse mbdelo de integração parece evoluir na medida em que se percebe e se define a participação como urna ação sistemática e con- tínua no processo decisório do setor saúde, incorporando, gradativamente, os diversos segmentos re-presentativos, em particular, o de profissionais de saúde.

\section{INTEGRAÇÃO ENTRE SEGMENTOS SOCIAIS E O PODER PÚBLICO: BASE TEÓRICA}

As formas de integração entre interesses organizados e o poder público procuram enfatizar o direito formal para influenciar as decisões governamentais, através de uma participação rotineira dos segmentos sociais na elaboração de políticas $\left({ }^{(9)}\right.$. A tendência para integração de representações dos segmentos sociais na administração pública brasileira, introduzidos por iniciativa govemamental e, em particular, no setor saúde através da criação de Conselhos de Saúde afinam-se com as concepções do arranjo institucional incorporativo e o tipo induzido de participação $(7,10,13)$.

A estratégia de criação de canais institucionalizados de relacionamento entre governo e representação dos segmentos sociais parece decorrer, entre outros fatores, de crescentes demandas por participação e aumento da crítica externa, associadas às mudanças político-institucionais ocorridas na última década. Desse modo, a necessidade de um instrumento para coordenação dos diferentes interesses pelos setores governamentais parece impulsionar o governo a criar estruturas elaboradas de articulação entre a administração pública e a sociedade civil, e que caracterizam o tipo induzido de participação. Deve-se notar, no entanto, que as críticas aos modelos institucionais colegiados e induzidos recaem nos contomos excessivamente pejorativos que tais arranjos podem manifestar. Os riscos para formas colegiadas de integração, na prática da administração pública são, de um modo geral, decorrentes das mesmas tomarem-se instrumentos de manipulação e cooptação de lideranças, em favor da legitimação de decisões previamente tomadas $(6,9,10)$.

De acordo com OLSEN(9), o exercício da participação dos segmentos organizados nas decisões da administração pública, através da criação de diferentes tipos de instâncias colegiadas governamentais (conselhos, juntas, comitês, comissões) caracteriza a forma de integração por regras especificas de procedimento. 
Esta forma de integração parece tomar possivel tanto uma participação mais sistemática, quanto ampliar as oportunidades de influências nas políticas públicas, apesar da possibilidade de dominação e manipulação por um ou mais segmentos, conforme mencionado.

As regras de procedimento especificam e definem os direitos de participação, isto é, quem deve participar do corpo de tomadores de decisão, bem como os problemas e soluções relevantes e os modos de negociação destas questões. Estes aspectos revelam dois elementos básicos na análise da criação de Conselhos: a composição e o funcionamento. Em relação a este segundo elemento, GONDIM(6) aponta três fatores importantes a serem observados na criação do órgão colegiado que, de um modo geral, irão definir o processo participativo: 1) o caráter decisório (se deliberativo ou consultivo); 2) a adotação de normas e regras para realização das atividades, incluindo atribuições dos conseIheiros; e 3) a interdependência entre o saber popular e o saber profissional que, associados, constituem uma necessidade para um efetivo desenvolvimento das dimensões técnica e política do processo participativo. É nessa dimensão que os profissionais e trabalhadores atuantes no SUS devem ter assegurada a sua participação nos Conselhos de Saúde, considerando o caráter multiprofissional das equipes que atuam nos serviços. Para que essa participação ocorra da maneira mais abrangente possível, é necessário um entendimento entre os representantes das diversas profissões envolvidas(3).

\section{METODOLOGIA}

A presente investigação seguiu um delineamento não-experimental, de natureza exploratória e descritiva, com base nas concepções de pesquisa de levantamento(12).

A população de estudo foi caracterizada pelo conjunto de 51 Conselhos Municipais de Saúde, criados nos municípios que assinaram o Convênio de Municipalização no Estado de Santa Catarina, no período de 1990 a 1992, em cumprimento aos requisitos do artigo quarto da Lei federal 8.142/90. Definiu-se por objeto de observação os profissionais da categoria de enfermagem, integrante destes Conselhos.

Os dados foram extraídos basicamente de fonte secundária, obtidos com o auxílio de uma planilha de levantamento dos dados contidos em Leis Municipais de Criação do Conselho de Saúde e Portarias de Nomeação dos membros-conselheiros, confrontados através da técnica de análise documental(12), que favoreceu uma interpretação predominantemente descritiva, auxiliada por procedimentos estatísticos de distribuição de frequências.

\section{ANÁLISE E INTERPRETAÇÃO DOS DADOS}

Com a aprovação da Lei Federal 8.142/90, os gestores do Sistema Único de Saúde (SUS) deram início à operacionalização dos requisitos legais exigidos para a capacitação gerencial na sua esfera de atuação.

O processo de criação de Conselhos Municipais de Saúde (CMS) depende de vários fatores, isolados ou conjuntos, envolvendo, entre outros, a mobilização da Câmara Municipal, negociação e interesse político dos níveis decisórios, o conhecimento técnico-operacional, bem como divulgação e pressão dos movimentos sociais favoráveis à sua criação. Além destes, deve-se destacar a assimilação por parte dos segmentos interessados das possíveis vantagens advindas com a criação desta instância colegiada, tidas como democratização das decisões, exercício do controle sopial nos assuntos do setor, aporte de recursos, implementação do sistema de saúde local. Na dependência da combinação destes fatores, a criação do ConseIho de Saúde pode se dar de modo mais ou menos rápido.

Até o ano de 1992, dos municípios de Santa Catarina, caracterizados, em sua maioria (92\%) como de pequeno porte, isto é, com menos de 50 mil habitantes, 51 dos 217 municípios (representando 23,5\% do total do Estado) conseguiram cumprir as exigências legais com vistas, principalmente, à assinatura do convênio de Municipalização. Este previa repasse de recursos financeiros direta e automaticamente do governo federal aos Fundos Municipais de Saúde, de forma suplementar ao repasse de custeio por prestação de serviços, a título de estímulo, o chamado Fator de Estímulo à Municipalização (FEM). Estes municipios criaram seus conseIhos de acordo com os pressupostos previstos (paridade, natureza deliberativa, caráter perma- 
Tabela 1: Número de representantes dos Conselhos Municipais de Saúde por regiōes do Estado, até 1992.

\begin{tabular}{|c|c|c|c|c|c|}
\hline \multirow[t]{2}{*}{ Regiōes do Estado } & \multirow{2}{*}{$\begin{array}{c}\text { Total de } \\
\text { Municipios } \\
\text { na Região }\end{array}$} & \multicolumn{2}{|c|}{$\begin{array}{l}\text { Municipios } \\
\text { Capacitados }\end{array}$} & \multirow[t]{2}{*}{ Municipios } & \multirow{2}{*}{$\begin{array}{l}\text { Número de } \\
\text { Representan } \\
\text { tes no CMS }\end{array}$} \\
\hline & & FA & FR $(\%)$ & & \\
\hline 1. Alto Irani & 09 & 02 & 4 & $\begin{array}{l}\text { Abelardo Luz } \\
\text { Galvăo }\end{array}$ & $\begin{array}{l}16 \\
16\end{array}$ \\
\hline 2. Rio do Peixe & 10 & 05 & 10 & $\begin{array}{l}\text { Fraibugo } \\
\text { Lebon Regis } \\
\text { Salto Veloso } \\
\text { Santa Cecilia } \\
\text { Timbo Grande }\end{array}$ & $\begin{array}{l}10 \\
12 \\
16 \\
14 \\
12\end{array}$ \\
\hline 3. Alto Uruguai & 12 & - & - & - & - \\
\hline 4. Alto Vale do Itajaí & 24 & 05 & 10 & $\begin{array}{l}\text { Imbuia } \\
\text { Petrolândia } \\
\text { Rio do Oeste } \\
\text { Salete } \\
\text { Trombudo Central }\end{array}$ & $\begin{array}{l}10 \\
10 \\
12 \\
12 \\
14\end{array}$ \\
\hline 5. Extremo Oeste de SC & 13 & 03 & 6 & $\begin{array}{l}\text { Guaraciaba } \\
\text { Iporá do Oeste } \\
\text { Itapiranga }\end{array}$ & $\begin{array}{l}18 \\
12 \\
14 \\
\end{array}$ \\
\hline 6. Extremo Sul Catarinense & 10 & 02 & 4 & $\begin{array}{l}\text { Santa Rosa do Sul } \\
\text { Sombrio }\end{array}$ & $\begin{array}{l}10 \\
08\end{array}$ \\
\hline 7. Foz do Rio Itajal & 10 & 03 & 6 & $\begin{array}{l}\text { Navegantes } \\
\text { Penha } \\
\text { Piçarras }\end{array}$ & $\begin{array}{l}12 \\
14 \\
08\end{array}$ \\
\hline 8. Meio Oeste Catarinense & 14 & 02 & 4 & $\begin{array}{l}\text { Erval Velho } \\
\text { Herval do Oeste }\end{array}$ & $\begin{array}{l}20 \\
14\end{array}$ \\
\hline 9. Médio vale do Itajal & 14 & 04 & 8 & $\begin{array}{l}\text { Ascurra } \\
\text { Blumenau } \\
\text { Dr. Pedrinho } \\
\text { Timbó } \\
\end{array}$ & $\begin{array}{l}10 \\
22 \\
08 \\
22\end{array}$ \\
\hline 10. Oeste de SC & 19 & 02 & 4 & $\begin{array}{l}\text { Iraceminha } \\
\text { Uniâo do Oeste }\end{array}$ & $\begin{array}{l}10 \\
08\end{array}$ \\
\hline 11. Planalto Norte & 04 & - & - & - & - \\
\hline 12. Regiâo Carbonifera & 08 & 07 & 13 & $\begin{array}{l}\text { Criciúma } \\
\text { Forquilhinha } \\
\text { Içara } \\
\text { Lauro Muller } \\
\text { Morro da Fumaça } \\
\text { Nova Veneza } \\
\text { Sideropolis }\end{array}$ & $\begin{array}{l}24 \\
10 \\
14 \\
16 \\
08 \\
10 \\
14\end{array}$ \\
\hline 13. Nordeste de SC & 08 & 03 & 6 & $\begin{array}{l}\text { Garuva } \\
\text { Itapoá } \\
\text { Såo Bento do Sul }\end{array}$ & $\begin{array}{l}22 \\
16 \\
28\end{array}$ \\
\hline 14. Regiāo de Laguna & 16 & 08 & 15 & $\begin{array}{l}\text { Armazém } \\
\text { Braço do Norte } \\
\text { Gráo Pará } \\
\text { Gravatal } \\
\text { Laguna } \\
\text { Rio Fortuna } \\
\text { São Ludgero } \\
\text { Sáo Martinho }\end{array}$ & $\begin{array}{l}08 \\
08 \\
18 \\
10 \\
18 \\
10 \\
10 \\
16\end{array}$ \\
\hline 15. Regiåo Serrana & 13 & 02 & 4 & $\begin{array}{l}\text { Lages } \\
\text { Urubici }\end{array}$ & $\begin{array}{l}12 \\
08\end{array}$ \\
\hline 16. Regiăo do Contestado & 06 & - & - & - & - \\
\hline 17. Vale do Itapocu & 06 & 01 & 2 & Barra Velha & 12 \\
\hline 18. Grande Florianópolis & 21 & 02 & 4 & $\begin{array}{l}\text { Alfredo Wagner } \\
\text { Anitápolis }\end{array}$ & $\begin{array}{l}08 \\
06\end{array}$ \\
\hline TOTAL & 217 & 51 & 100 & & 670 \\
\hline
\end{tabular}


Incidência

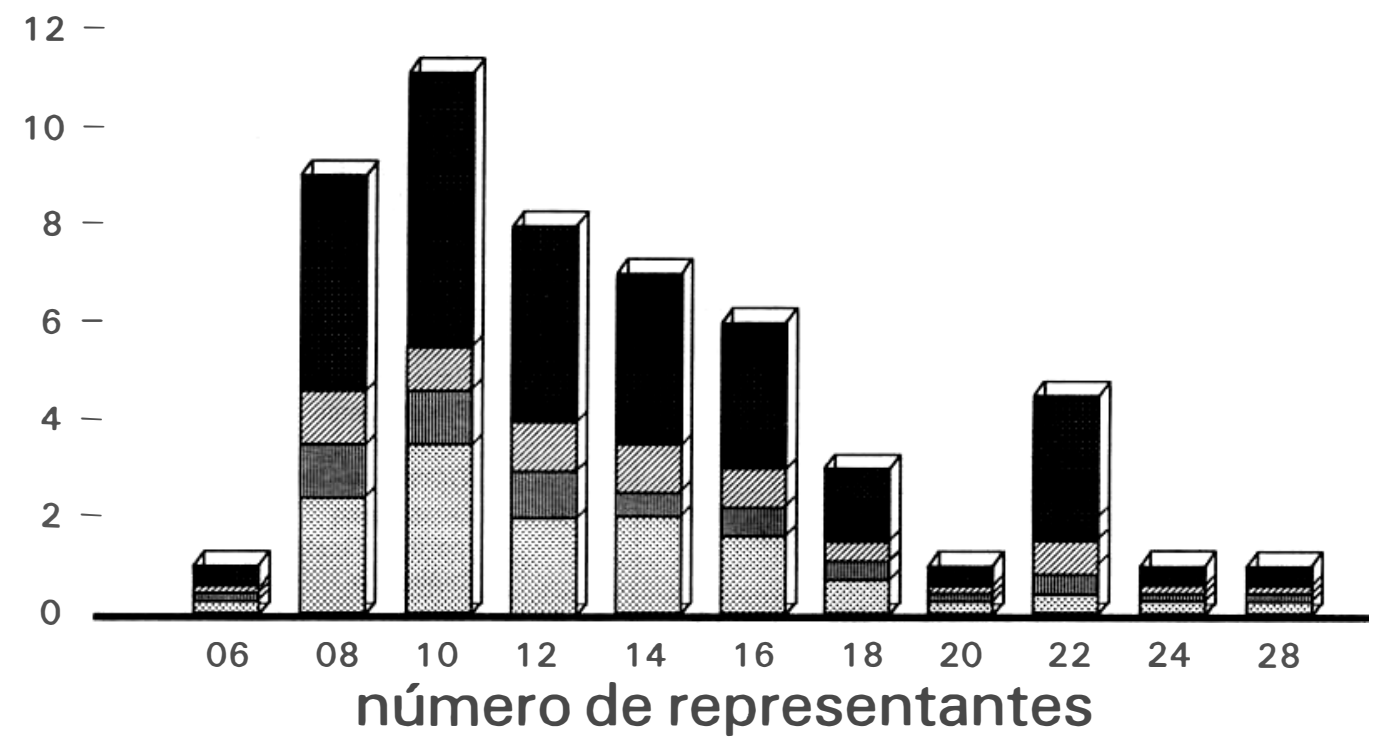

governo

prestador

Difles profissional

úsuarios

Fonte: SES/SC

nente, etc), num período que variou entre maio de 1991 a abril de 1992, com uma concentração de $59 \%$ das Leis de criação nos meses de novembro a dezembro de 1991, ou seja, um ano após a publicação da Lei Orgânica da Saúde.

Para uma efetiva implantaçåo dos ConseIhos Municipais de Saúde, acompanha a lei de criaçåo, a respectiva Portaria de Nomeação de seus membros-conselheiros. Em média, os gestores municipais demoraram um mês ( $62 \%$ dos municípios) para regularizar a situação de nomeação. O extremo máximo para elaboração da portaria após a aprovação da lei foi de um período de seis meses.

Procurou-se levantar a representação dos Conselhos Municipais de Saúde capacitados segundo a norma vigente, por regiőes do Estado. Foi possível verificar que, proporcionalmente ao número de municípios, as regiões de Laguna e Carbonífera sobressaíram-se na conclusão dos dispositivos legais (criação de Conselhos e Fundos de Saúde, elaboração de Planos de Saúde, de Planos de Cargos, Carreira e Salários e de relatórios de Gestão, bem como compromisso de contrapartida de recursos orçamentários para a saúde).
Cabe notar que o Conselho Nacional de Saúde recomenda, na resolução de número 35 , que a composição dos Conselhos de Saúde não seja superior a 20 membros, nem inferior a 10. Estão de acordo com essa recomendação 35 (70\%) dos Conselhos Municipais de Saúde estudados, ultrapassando o número de 20 membros somente $5(9,8 \%)$, os quais 2 de grande e um de médio portes. Há que se considerar a dificuldade que municípios de pequeno porte (como é o caso da maioria dos municípios do Estado) apresentam para congregar um número suficiente de entidades representativas dos segmentos envolvidos para comporem o Conselho, de modo a atender a recomendação (superior a 10 entidades) e satisfazer a condição de paridade. A tabela 1 mostra a distribuição do número de representantes dos conselhos Municipais de Saúde capacitados segundo a norma vigente, por regiões do Estado.

Os dados referentes à composição dos CMS foram agrupados de acordo com o número total de representantes (vide tabela 1). Nos 51 CMS estudados, existem 670 representações, das quais $335(50 \%)$ de usuários. A outra metade é caracterizada por $178(26 \%)$ representantes go- 


\section{Figura 2: Representação dos Profissionais de Saúde nos CMC, por categoria profissional}

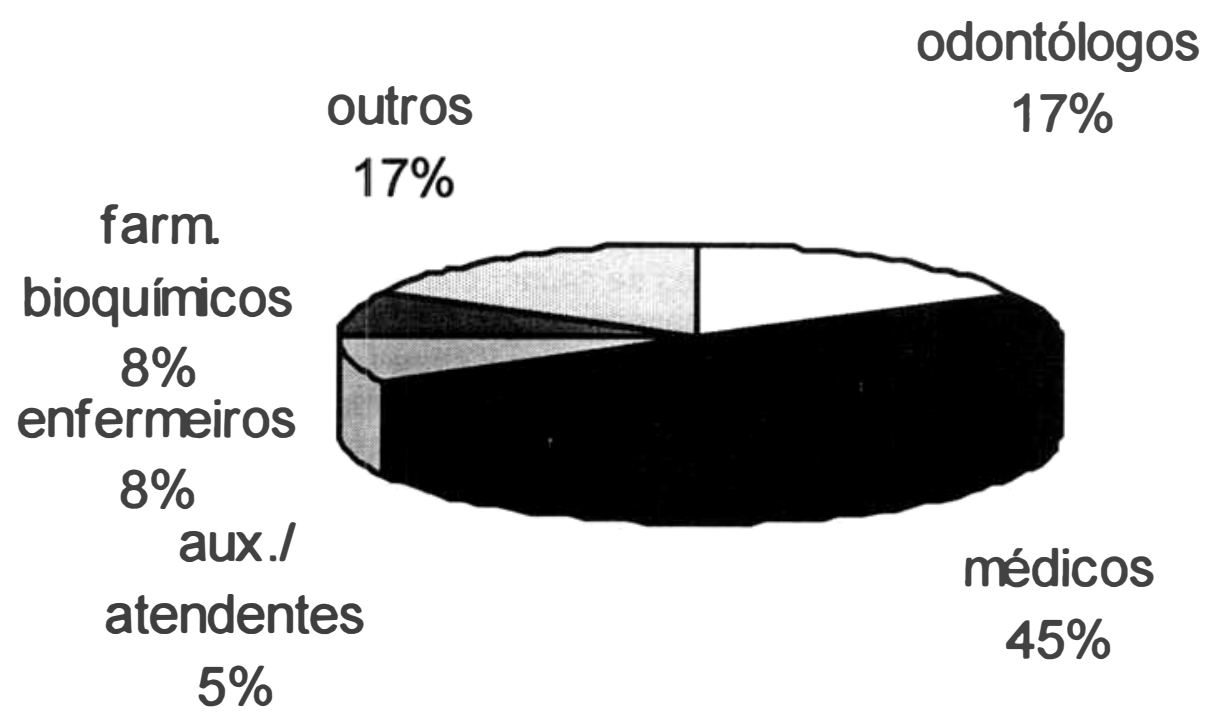

vemamentais, $77(12 \%)$ prestadores de serviços e $80(12 \%)$ profissionais de saúde, computados em termos relativos e analisados comparativamente entre os CMS. A maior incidência segundo 0 número de representantes nos CMS é apresentada naqueles compostos por $10 \mathrm{mem}$ bros, seguidos por CMS com 8 e 12 membros. Apresentaram apenas uma incidência ConseIhos compostos por 6, 20, 24 e 28 conselheiros, conforme mostra a Figura 1.

Respeitada a paridade com o segmento usuário, verifica-se, nos demais segmentos, maior incidência no número de representantes do segmento govemamental, em especial naqueles CMS compostos por 10 membros (cuja proporção verificada foi de 3 representantes do governo, 1 de prestador de serviço e 1 de profissional de saúde), bem como os compostos por 12 e 14 conselheiros (na proporção 4:1:1 e 5:1:2, respectivamente). Observou-se que $77 \%$ dos profissionais que se encontram no segmento governamental são médicos, ocupando a função de Secretário Municipal de Saúde.
As representaçőes da categoria de prestadores de serviços, com uma incidência proporcional à dos profissionais de saúde, para comporem os CMS devem apresentar, obrigatoriamente, vínculo com o SUS. Considerando que a maioria dos municípios catarinenses são de pequeno porte, representaram o segmento de prestador de serviço os diretores de hospitais públicos (próprios ou conveniados), e/ou os representantes de unidades de saúde (posto, centro ou policlínica) municipais ou municipalizadas. Tanto as entidades hospitalares quanto as ambulatoriais mostraram profissionais de saúde representando este segmento. As categorias identificadas foram as de médico e farmacêutico-bioquímico (para os hospitais) e atendentes de saúde pública e odontólogos (para os ambulatórios).

Dentro do segmento de profissionais de saúde (12\% do total das representações), procurou-se levantar as diferentes categorias representadas, encontrando-se $45 \%$ médicos, $17 \%$ odontólogos, $8 \%$ enfermeiros, $8 \%$ farmacêuticos-bioquímicos, $5 \%$ auxiliares de enfermagem e atendentes de 
saúde pública e $17 \%$ descritos como profissionais de saúde (sem especificação da categoria), conforme apresentado na Figura 2.

Comparativamente às demais categorias profissionais, e mesmo em relação à representatividade da força de trabalho da enfermagem, pode-se considerar bastante baixo e insuficiente o percentual dos representantes das entidades de enfermagem no segmento de profissionais de saúde. Excetuando-se a de odontólogos, as demais categorias somadas, incluindo o enfermeiro, não atingem sequer o percentual da representação médica, sugerindo a manutenção do status quo no campo de participação e influência no processo de decisão e controle das políticas de saúde. Além disso, os dados parecem refletir a necessidade de um reordenamento de enfermagem em direção à novas opções para desenvolvimento de sua prática, fundamentada no princípio da integralidade do SUS, em vista do grande espaço existente na área de gerenciamento local/municipal das ações e serviços de saúde.

\section{CONCLUSÕES E PERSPECTIVAS PARA A ATUAÇÃO DO ENFERMEIRO EM INSTÂNCIAS COLEGIADAS DE DECISÃO}

O processo de reorganização setorial e a situação atual do SUS parece realçar a importância da integração dos profissionais de saúde através das instâncias colegiadas de decisão. As atribuições dos Conselhos de Saúde envolvem aspectos tão importantes relacionados, entre outros, com a formulação das políticas de saúde, definição de alocação de recursos para o setor, determinação de prioridades, acompanhamento e controle das ações e prestação de serviços e fiscalização dos órgãos públicos e privados componentes do sistema de saúde.

A participação do enfermeiro, neste contexto, deve ser sublinhada em virtude, principalmente, de sua característica e formação profissional, que parece melhor harmonizar-se com o princípio de integralidade da atenção á saúde defendida e buscada pelo SUS. Esta característica profissional, já reforçada pelo Conselho Federal de Enfermagem(2), toma o enfermeiro um dos participantes potenciais dos Conselhos de
Saúde, acentuando a tendência para o gerenciamento das ações e senviços de saúde.

Em vista destes fatos, o intuito de identificar a representação dos profissionais de saúde nos conselhos Municipais de Saúde, bem como, caracterizar a representação do enfermeiro e da enfermagem neste segmento foi justificado, possibilitando verificar diferenças marcantes entre o número de representantes dos segmentos que compõem os não-usuários (governo, prestadores de serviço e profissionais de saúde), bem como, entre as categorias que compõem o segmento profissionais de saúde. A despeito da massa significativa que representa a categoria enfermagem na força de trabalho das instituições de saúde, comparativamente às demais categorias, sua integração junto aos Conselhos estudados mostrou-se bastante baixa. Observou-se a predominância da categoria médica nos segmentos de profissionais e governamentais (em geral como ocupante do cargo de Secretário Municipal de Saúde), sugerindo que este, ainda, é um campo a ser explorado e ocupado pelas demais categorias, buscando o sentido multiprofissional tanto nas práticas político-gerenciais, como na condução e transformação do modelo assistencial vigente na saúde.

Assim, é de se recomendar que os enfermeiros como categoria profissional, não optem por esperar passivamente a cristalização dos Conselhos de Saúde, mas sim por participar intensamente da sua criação e implementação, alcançando desse modo a representatividade necessária à participação da enfermagem na formulação das políticas de saúde, participação esta por todos os títulos, importante pelos motivos acima discutidos. Deve ser notado que a participação da categoria médica no Conselho Nacional de Saúde já está garantida no Decreto que o regulamenta. As demais categoria profissionais atuantes na área de saúde concorrerão para ocupar as outras duas vagas restantes, destinadas aoj demais profissionais. Além disso, as outras esferas de governo (e suas instâncias colegiadas de decisão) representam espaço a ser ocupado pelo enfermeiro, na sua busca por representatividade e participação nas decisões políticas e administrativas neste setor. 


\section{REFERÊNCIAS BIBLIOGRÁFICAS}

1. CARVALHO, A.N. e OLIVEIRA, F.V.S. A produçăo do serviço de enfermagem na atual conjuntura de saúde - contribuiçáo ao debate. Rev. Bras. Enferm., Brasília, n.43, p.7-13, jan./dez. 1990.

2. COFEN - O exerclcio da Enfermagem nas instituiçôes de saúde no Brasil: 1982/1983. Conselho Federal de Enfermagem/Associaçăo Brasileira de Enfermagem, v.1. Rio de Janeiro, 1985.

3. CONASEMS - Conselho Nacional de Secretários Municipais de Saúde. Publicaçőes Técnicas. n.3, set./out. 1991.

4. CONVÊNIO SUDS/88, Secretaria do Estado da Saúde, Santa Catarina, 1988.

5. CORDEIRO, Hésio. Saúde e Trabalho no Brasil. 2. ed. Petrópolis: Vozes, 1983.

6. GONDIM, Linda M. A participaçăo popular na elaboraçåo do Plano Diretor: aspectos operacionais. Rio de Janeiro: IBAM. 1990 (mimeo).

7. MACHADO, Francisco A. As possibilidades de controle social das políticas públicas. Revista de Administração Pública, Rio de Janeiro, v.22, n.1, p.32-49, jan./mar. 1988.
8. OLIVEIRA, J.A.A. e TEIXEIRA, S.M.F. (Im)Previdencia Social: 60 anos de história da Previdéncia no Brasil. Petrópolis: Vozes/Abrasco, 1986.

9. OLSEN, Johan P. Integrated Organizational Participation in Govemment. In: NYSTROM, Paul C., STARBUCK, William H. Handbook of Organization Desing. New York: Oxford University Press, 1981, v.2.

10. PRATES, António A.P. e ANDRADE, Luis A.G. Notas sobre o modelo de Planejamento Participativo: o caso de Minas Gerais. Revista de Administraçăo Pública, Rio de Janeiro, v.19, n.2, p.132-152, abr./jun. 1985.

11. RICHARDSON, R.J. et al. Pesquisa Social: métodos e técnicas. Sâo Paulo: Atlas, 1985.

12. SELLTIZ, Claire et al. Métodosde Pesquisa nas Relaçóes Sociais. Sáo Paulo: EDUSP, 1974.

13. SOMARRIBA, Maria M.G. Participaçăo Popular e Distritos Sanitários. Brasília: Organizaçăo Panamericana de Saúde. Oficina Regional de Brasília. 1988 (Série Desenvolvimento de Serviços de Saúde. n.3).

Recebido para publicaçáo em 28.03.94. 